\title{
Produção de esporos e efeito da temperatura e luminosidade sobre germinação e infecção de Pseudocercospora vitis em videira
}

\author{
Aline José Maia ${ }^{1}$, Kátia Regina Freitas Schwan-Estrada ${ }^{2}$, Cacilda Márcia Duarte Rios Faria ${ }^{1}$, Leandro Alvarenga \\ Santos ${ }^{1}$, Juliana Batista Santos Oliveira ${ }^{2}$, Rafaela Cristina dos Santos ${ }^{1}$
}

\begin{abstract}
${ }^{1}$ Universidade Estadual do Centro-Oeste, Guarapuava, PR, Brasil. ${ }^{2}$ Universidade Estadual de Maringá, Maringá, PR. Brasil.
*Autor para correspondencia: Leandro Alvarenga Santos (leandro.alvarenga.s@hotmail.com)

Data de chegada: 09/03/2015. Aceito para publicação em: 09/06/2015.
\end{abstract}

$10.1590 / 0100-5405 / 2080$

\section{RESUMO}

Maia, A.J.; Schwan-Estrada, K.R.F.; Faria, C.M.D.R.; Santos, L.A.; Oliveira, J.B.S.; Santos, R.C. Produção de esporos e efeito da temperatura e luminosidade sobre germinação e infecção de Pseudocercospora Vitis em videira. Summa Phytopathologica, v.41, n.4, p.287-291, 2015.

Dentre as doenças fúngicas da videira, merece destaque a manchada-folha causada por Pseudocercospora vitis. As condições favoráveis ao desenvolvimento da mancha-da-folha ainda não foram totalmente determinadas. Sabe-se que a formação de conídios ocorre sob condições de alta umidade e são disseminados pela ação do vento, iniciando novas infecções. Para aumentar o conhecimento sobre a produção, germinação e infecção do patógeno foram realizados três experimentos. No primeiro experimento, avaliou-se a produção de esporos de P. vitis, nos meios de cultura: BDA (batata-ágar-dextrose);
BDA+Leite de coco (5\%); BDA+extrato de uva cv. Isabel (5\%); ST (suco de tomate-carbonato de cálcio-ágar); ST+leite de coco (5\%); ST+extrato de uva cv. Isabel (5\%). Houve esporulação em todos os meios testados e diferentes períodos de incubação. No segundo experimento, verificou-se que a temperatura de $25{ }^{\circ} \mathrm{C}$ propiciou maior porcentagem de conídios germinados e que houve maior germinação na ausência de luz. No terceiro experimento observou-se que a temperatura de $20{ }^{\circ} \mathrm{C}$ propiciou maior severidade da mancha-da-folha em mudas de videiras, após 48 horas de incubação no escuro.

Palavras-chave: epidemiologia, conídio, uva, mancha das folhas

\section{ABSTRACT}

Maia, A.J.; Schwan-Estrada, K.R.F.; Faria, C.M.D.R.; Santos, L.A.; Oliveira, J.B.S.; Santos, R.C. Spore production and effect of temperature and light on germination and infection by Pseudocercospora vitis in grape plants. Summa Phytopathologica, v.41, n.4, p.287-291, 2015.

Among the fungal diseases of vine, leaf spot caused by Pseudocercospora vitis is worthy of note. The favorable conditions for the development of leaf spot have not been fully determined yet. Conidia are known to be formed under high humidity conditions and spread by the wind, initiating new infections. To increase the knowledge on production, germination and infection by this pathogen, three experiments were conducted. In the first experiment, we evaluated the production of $P$. vitis spores on the culture media: PDA (potato dextrose agar); PDA + coconut milk (5\%); PDA +
'Isabel cv.' grape extract (5\%); ST (tomato juice-calcium carbonate-agar); $\mathrm{ST}+$ coconut milk (5\%); ST + 'Isabel cv.' grape extract (5\%). There was sporulation on all tested media and different incubation periods. In the second experiment, the temperature of $25^{\circ} \mathrm{C}$ provided higher percentage of germinated conidia and there was greater germination in the absence of light. In the third experiment, the temperature of $20^{\circ} \mathrm{C}$ led to greater severity of the leaf spot in vine seedlings after 48 hours of incubation in the dark.

Additional keywords: epidemiology, conidium, grape, leaf spot.

A videira (Vitis sp.) é uma cultura perene susceptível a uma ampla gama de agentes patogênicos. Dentre as doenças encontra-se a mancha-da-folha causada pelo fungo Mycospharella personata Higgins, (fase imperfeita, Pseudocercospora vitis (Léveillé) Spegazzini, 1910, sinonímia de Isariopsis clavispora (Berkeley \& Cooke) Saccardo 1886),), morfologicamente os conídios apresentam 5-10 septos, 25-90 $\mu \mathrm{m}$ de comprimento e 5-8 $\mu \mathrm{m}$ de largura (18).

A mancha das folhas por ser uma doença que ocorre no final do ciclo vegetativo, não desperta atenção dos produtores, no entanto quando não são realizados os tratamentos após a colheita, esta doença pode ocasionar queda prematura das folhas (19). Segundo Bennett et al. (4), a redução da área foliar pode restringir o acúmulo de carboidratos, tendo como consequências impactos negativos no florescimento e no rendimento da produção nos anos seguintes.
Como se sabe o controle dessa doença tem sido feito principalmente por meio da utilização de defensivos agrícolas. No entanto, o uso intensivo e indiscriminado de fungicidas sistêmicos a longo prazo tem causado diversos problemas, como a seleção de patógenos resistentes aos princípios ativos mais utilizados, além de do maior risco para o ambiente (15).

As condições favoráveis ao progresso da mancha-da-folha ainda não estão determinadas. Sabe-se, no entanto, que a formação de conídios ocorre sob condições de alta umidade, os quais são normalmente disseminados pela ação do vento, iniciando novas infecções (19). Entretanto, diversas variáveis são capazes de induzir ou inibir o desenvolvimento vegetativo e reprodutivo da maioria dos fungos, dentre elas as mais importantes são a temperatura e a luminosidade (8). A temperatura modula a produção de proteínas e 
enzimas responsáveis pela manutenção da célula fúngica, enquanto que a luminosidade exerce efeito direto sobre a mesma, induzindo ou inibindo a formação de estruturas de reprodução, embora haja algumas espécies que são indiferentes à quantidade e/ou qualidade da luz (6).

As espécies do gênero Pseudocercospora, caracterizam-se pelo lento crescimento e pela reduzida esporulação em meios de cultura, essa característica tem limitado os estudos com este grupo de patógenos. A composição do meio de cultura, que determina a quantidade e qualidade do crescimento micelial e esporulação dos fitopatógenos (5).

Neste contexto, o objetivo deste trabalho foi avaliar diferentes meios de cultivo na esporulação, bem como o efeito da temperatura e luminosidade na germinação de conídios e na infecção de $P$. vitis em videiras cv Isabel e Bordô (Vitis labrusca L.) e o progresso temporal da mancha-da-folha.

\section{MATERIAL E MÉTODOS}

\section{Produção de esporos em diferentes meios de cultivo}

Para este experimento foi realizado isolamento do patógeno $P$. vitis, a partir de folhas de videira cv. Isabel com lesões, provenientes da região de Guarapuava-PR. O isolado foi mantido em meio de cultura BDA (batata-dextrose-ágar).

Para avaliar os diferentes tipos de meio de cultivo na esporulação de $P$. vitis, os seguintes meios de cultivo foram testados: BDA (Batatadextrose -ágar); BDA+leite de coco (5\%); BDA+extrato de uva cv. Isabel (5\%); ST (suco de tomate-carbonato de cálcio-ágar); ST+Leite de coco (5\%); ST+extrato de uva cv. Isabel (5\%). Para realizar a produção do inóculo micelial foram preparados $30 \mathrm{~mL}$ de meio líquido para todos os tratamentos, os quais foram autoclavados a $120^{\circ} \mathrm{C}$ por $20 \mathrm{~min}$. Três discos de $9 \mathrm{~mm}$ de diâmetro foram retirados de colônias de $P$. vitis cultivadas por 25 dias em BDA e adicionados aos meios líquidos. Estes foram colocados em incubadora refrigerada sob agitação a 115 rpm, à temperatura de $25^{\circ} \mathrm{C}$, na ausência de luz, por 72 horas. Desta suspensão, uma alíquota de $500 \mu \mathrm{L}$ foi transferida para o centro das placas de Petri com os respectivos meios de cultura. O delineamento experimental foi inteiramente casualizado com seis tratamentos (diferentes composições de meios de cultura) e cinco repetições. As placas foram mantidas em câmara de crescimento a $25^{\circ} \mathrm{C}$ e fotoperíodo de 12 horas. Após 96,120 , 144 e 168 horas de incubação foi quantificado o número de esporos, por meio de leitura em câmara de Neubauer. No primeiro e último dia de avaliação foram mensuradas as dimensões dos esporos. Para a validação dos dados o experimento foi repetido duas vezes.

Os valores foram submetidos à análise de variância e quando atendidos os pressupostos da ANOVA, realizou-se o teste de agrupamento de médias Tukey ao nível de 5\% probabilidade, por meio do programa estatístico SISVAR (11).

\section{Efeito da temperatura na germinação de conídios}

Para o teste de germinação foi utilizado uma alíquota de $40 \mu \mathrm{L}$ da suspensão de esporos $\left(1 \times 10^{4}\right.$ conídios $\left.\mathrm{mL}^{-1}\right)$ a qual foi transferida para o orifícios da placa de teste ELISA. Na sequência as placas foram mantidas no escuro e sob luz contínua, em estufa incubadora, nas temperaturas de $15,20,25$ e $30^{\circ} \mathrm{C}$, por períodos de $4,6,8,12$ horas. A germinação foi paralisada utilizando $20 \mu \mathrm{L}$ do corante azul algodão de lactofenol. Foram avaliados 100 esporos, estabelecendo o percentual de esporos germinados, com auxilio de microscópio ótico (x400). Foram considerados germinados os esporos com tubo germinativo de comprimento igual ou superior ao comprimento do esporo.

Os resultados foram submetidos à análise de variância e as médias foram utilizadas para realizar a regressão polinomial ao nível de 5\% probabilidade, por meio do programa estatístico SISVAR (11).

Efeito da temperatura na infecção de $P$. vitis em videira cv. Isabel

Estacas lenhosas de videria foram obtidas do pomar comercial do município de Marialva-PR, em seguida as estacas com ao menos cinco gemas foram introduzidas em vasos de plástico $(2 \mathrm{~L})$, contendo substrato Plantmax ${ }^{\circledR}$ e areia na proporção 1:1 (v/v).

As mudas de videira apresentavam aproximadamente 10 folhas, quando se inoculou suspensão de esporos na concentração de $10^{5}$ conídios $\mathrm{mL}^{-1}$, por meio de pulverização, até o ponto de escorrimento. Em seguida, as mudas foram submetidas às temperaturas de 15, 20, 25, 30 e $35^{\circ} \mathrm{C}$ em câmara de crescimento no tempo de incubação 48 horas. Após este período as plantas foram mantidas em casa de vegetação com temperatura média de $30{ }^{\circ} \mathrm{C} \pm 2{ }^{\circ} \mathrm{C}$ e umidade relativa de $70 \%$. $\mathrm{O}$ delineamento experimental foi inteiramente casualizado com cinco tratamentos (diferentes temperaturas) e quatro repetições.

Para quantificação da intensidade da doença avaliou-se a severidade das manchas necróticas com o uso de uma escala diagramática com notas de um a seis que correspondem a uma variação de 1,6\% a 40,2\% da área foliar lesionada (13). Com os dados de severidade foi determinada a área abaixo da curva de progresso das doenças (AACPD), segundo Campbell \& Madden (7). No total foram realizadas nove avaliações com intervalos de sete dias.

Com os resultados obtidos realizou-se à análise de variância e quando significativo realizou a regressão polinomial ao nível de 5\% probabilidade, por meio do programa estatístico SISVAR (11).

\section{RESULTADO E DISCUSSÃO}

\section{Diferentes meios de cultivo na esporulação de P.vitis}

Observou-se esporulação do patógeno em todos os meios testados e nos diferentes períodos de incubação (Tabela 1). Nos meios ST acrescido de leite de coco ( $1 \%$ ) e extrato de uva (1\%) foi observado maior esporulação em todos os tempos de incubação testados. Às 96, 144 e 168 horas de incubação os meios com ST apresentaram valores de médias cinco, doze e treze vezes, respectivamente, maiores que o meio BDA. No período de 120 horas após incubação, o meio contento apenas o Suco de tomate como fonte nutritiva apresentou valores de esporulação equivalente aos meios de ST acrescidos de extrato de uva (1\%) e leite de coco (1\%).

O meio ST é relatado como bom indutor de esporulação em várias espécies de fungos considerados de difícil isolamento e esporulação como, por exemplo, do gênero Cercospora (17). Brunelli et al. (6), trabalhando com o efeito de diferentes meios de cultura na esporulação de Cercospora zeae-maydis, agente causal da cercosporiose do milho, constataram que o meio ST induziu grande quantidade de conídios. Resultados semelhantes foram obtidos por Ávila et al. (3), ao avaliar a produção de biomassa micelial bem como a esporulação de Cercospora piaropi Tharp. verificando também que o meio ST induziu esporulação maior do patógeno quando cultivado por $120 \mathrm{~h}$ em agitação.

Para o comprimento e largura dos esporos, não houve diferença estatística entre os tratamentos as 96 horas de incubação (Tabela 2). No período de 168 horas após incubação o meio BDA acrescido com leite de coco (1\%) apresentou maior comprimento, não diferindo estatisticamente dos tratamentos ST e ST acrescido com leite de coco (1\%) (Tabela 2). Para variável largura dos esporos o meio ST acrescido de extrato de uva (1\%), BDA acrescido de leite de coco e ST 
Tabela 1. Esporulação de Pseudocercospora vitis $\left(10^{4}\right.$ conídios $\left.\mathrm{mL}^{-1}\right)$ em diferentes meios de cultura e períodos de incubação

\begin{tabular}{lllll}
\hline \multirow{2}{*}{ Meio de Cultivo } & \multicolumn{4}{c}{ Produção de esporos $\left(\mathbf{1 0}\right.$ conídios $\left.\mathbf{~} L^{-1}\right)$} \\
\cline { 2 - 5 } & $\mathbf{9 6}$ horas & $\mathbf{1 2 0}$ horas & $\mathbf{1 4 4 h o r a s}$ & $\mathbf{1 6 8}$ horas \\
\hline BDA & $11,3 \mathrm{c}$ * & $8,93 \mathrm{c}$ & $9,43 \mathrm{c}$ & $8,5 \mathrm{c}$ \\
BDA+Extrato de uva & $11,9 \mathrm{c}$ & $20,1 \mathrm{bc}$ & $31,4 \mathrm{c}$ & $36,9 \mathrm{bc}$ \\
BDA+Leite de coco & $27,6 \mathrm{bc}$ & $20,5 \mathrm{bc}$ & $37,5 \mathrm{bc}$ & $52,6 \mathrm{bc}$ \\
ST & $46,2 \mathrm{ab}$ & $50,4 \mathrm{bc}$ & $86,5 \mathrm{ab}$ & $60,4 \mathrm{ab}$ \\
ST+ Extrato de uva & $63,5 \mathrm{a}$ & $71,9 \mathrm{a}$ & $94,1 \mathrm{a}$ & $112,7 \mathrm{a}$ \\
ST+ Leite de coco & $53,5 \mathrm{a}$ & $76,8 \mathrm{a}$ & $113,6 \mathrm{a}$ & $116,7 \mathrm{a}$ \\
\hline CV (\%) & 32,32 & 47,93 & 51,80 & 39,86 \\
\hline Fc & 18,227 & 10,669 & 8,388 & 13,695 \\
\hline
\end{tabular}

*Médias seguidas de letras distintas minúsculas não diferem entre si pelo Teste de Tukey $(\mathrm{P}<0,05)$;

apresentaram maiores valores de média diferindo significativamente dos demais meios.

No presente trabalho observou-se que o meio ST acrescido com extratos de uva e Leite de coco apresentaram maior esporulação de $P$. vitis. De acordo com Nozaki et al. (16), os meios de cultivos preparados a partir de partes de plantas suscetíveis podem aumentar as chances de

Tabela 2. Tamanho do esporo de Pseudocercospora vitis em diferentes meios de cultura após 96 e 168horas de incubação

\begin{tabular}{lllll}
\hline \multirow{2}{*}{ Meios de cultivo } & \multicolumn{3}{l}{ Comprimento $(\mu \mathrm{m})$} & \multicolumn{2}{l}{ Largura $(\mu \mathrm{m})$} \\
\cline { 2 - 5 } & 96 horas $^{\mathrm{NS}}$ & 168 horas & 96 horas $^{\mathrm{NS}}$ & 168 horas \\
\hline BDA & 8,29 & $6,93 \mathrm{a}^{*}$ & 2,73 & $2,52 \mathrm{a}^{*}$ \\
BDA+Extrato de uva & 8,43 & $7,95 \mathrm{a}$ & 2,65 & $2,71 \mathrm{a}$ \\
BDA+Leite de coco & 9,94 & $11,06 \mathrm{~b}$ & 2,79 & $2,95 \mathrm{ab}$ \\
ST & 8,51 & $8,93 \mathrm{ab}$ & 2,80 & $2,87 \mathrm{ab}$ \\
ST+ Extrato de uva & 8,38 & $8,34 \mathrm{a}$ & 2,73 & $3,11 \mathrm{~b}$ \\
ST+ Leite de coco & 9,93 & $8,99 \mathrm{ab}$ & 2,72 & $2,73 \mathrm{a}$ \\
\hline CV (\%) & 16,5 & 14,71 & 4,3 & 9,18 \\
\hline Fc & 1,33 & 5,83 & 1,26 & 3,21
\end{tabular}

*Médias seguidas de letras distintas minúsculas não diferem entre si pelo Teste de Tukey $(\mathrm{P}<0,05)$;

NS: Variável não significativa de acordo com o Feste $\mathrm{F}$ esporulação de fungos fitopatogênicos, possivelmente por apresentarem carboidratos complexos mais adequados à produção de esporos.

Com base nos resultados obtidos neste trabalho o meio de cultivo composto de ST acrescido de extrato de uva e leite de coco mostrou-se como melhor opção para produção de esporos de $P$. vitis.

\section{Efeito da temperatura na germinação de conídios}

Para o teste de germinação de conídios com diferentes períodos de incubação na presença de luz observou-se efeitos quadráticos para os menores tempos de incubação (4 e 6 horas) e efeito lineares paras os demais (8 e 12 horas). Para os períodos de oito e doze horas de incubação, na presença de luz, a temperatura de $30^{\circ} \mathrm{C}$ propiciou a maior proporção de germinação (22 e $40 \%$ ), respectivamente (Figura 1 A). Para os períodos de menores tempos de incubação (4 a 6 horas) a temperatura de $25{ }^{\circ} \mathrm{C}$ apresentou maior porcentagem de conídios germinados 5,6 e 13,7\%, respectivamente.

$\mathrm{Na}$ ausência de luz, houve efeito quadrático para a germinação de conídios de $P$. vitis em função das diferentes temperaturas (Figura 1B) sendo que as temperaturas estimadas para a máxima germinação de conídios de $P$. vitis foram de $24,23,24$ e $26^{\circ} \mathrm{C}$ em 4, 6, 8 e 12 horas após incubação. A temperatura de $25{ }^{\circ} \mathrm{C}$ propiciou maior porcentagem $(67,95 \%)$ de conídios germinados em todos os períodos de avaliação.

Angelotti et al. (2), ao avaliar os efeitos de temperatura na germinação dos conídios de Uncinula necator, verificaram que o maior índice de germinação ocorreu sob temperaturas de 19 a $27^{\circ} \mathrm{C} \mathrm{e}$ o menor índice a $31^{\circ} \mathrm{C}$, não ocorrendo germinação a partir de $35^{\circ} \mathrm{C}$.

Casa et al . (9), com o objetivo de avaliar a influência da temperatura e do regime de luz no crescimento radial do micélio, na germinação dos conídios e na esporulação (produção de cirros) de Stenocarpella macrospora e de Stenocarpella maydis, verificaram que os conídios de $S$. macrospora e $S$. maydis não germinaram mesmo após $24 \mathrm{~h}$ de incubação nas temperaturas de 5 e $45{ }^{\circ} \mathrm{C}$, independentemente do regime de luz. As temperaturas entre 28 e $33{ }^{\circ} \mathrm{C}$ propiciaram a maior porcentagem de germinação dos conídios de $S$. maydis, enquanto os conídios de $S$. macrospora apresentaram maior germinação na faixa de temperatura entre 26 e $29^{\circ} \mathrm{C}$.

Os conídios de $P$. vitis germinaram em maior quantidade à medida que se elevou a temperatura e quando expostos por um período de
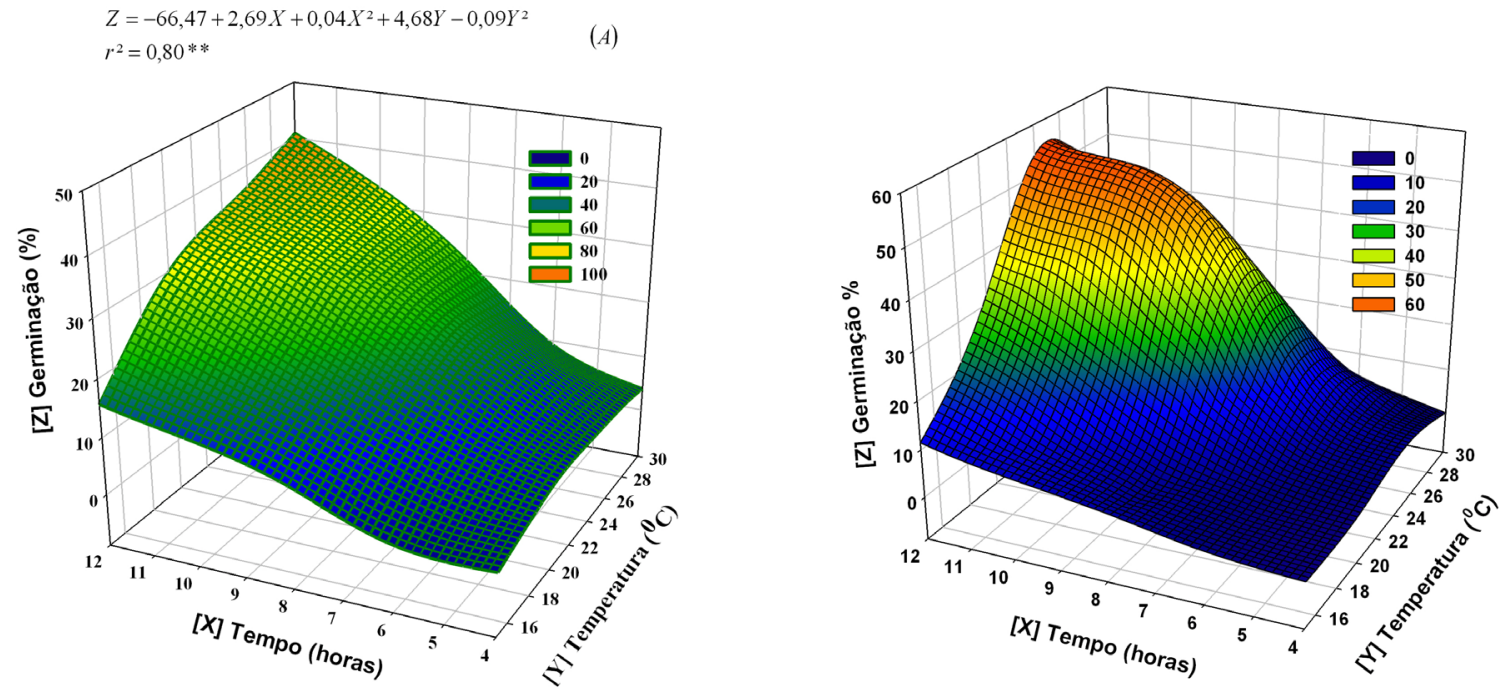

Figura 1. Germinação de Pseudocercospora vitis em diferentes temperaturas e períodos de incubação. A-claro e B-escuro, Maringá-PR. Dados transformados em raiz quadrada de $\mathrm{Y}+1.0-\mathrm{SQRT}(\mathrm{Y}+1.0)$. ** Significativo a $5 \%$ de probabilidade. 


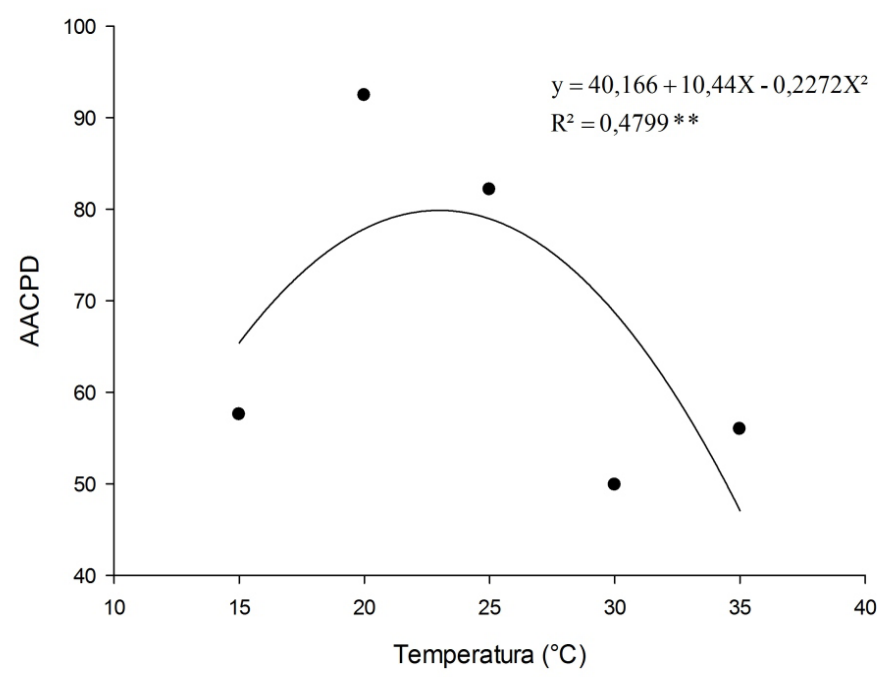

Figura 2. Área sob a curva de progresso da doença (AACPD) em mudas de videira cv. Isabel submetida a diferentes temperaturas após 48 horas de incubação em resposta a infecção de $P$. vitis. **Significativo a $5 \%$ de probabilidade.
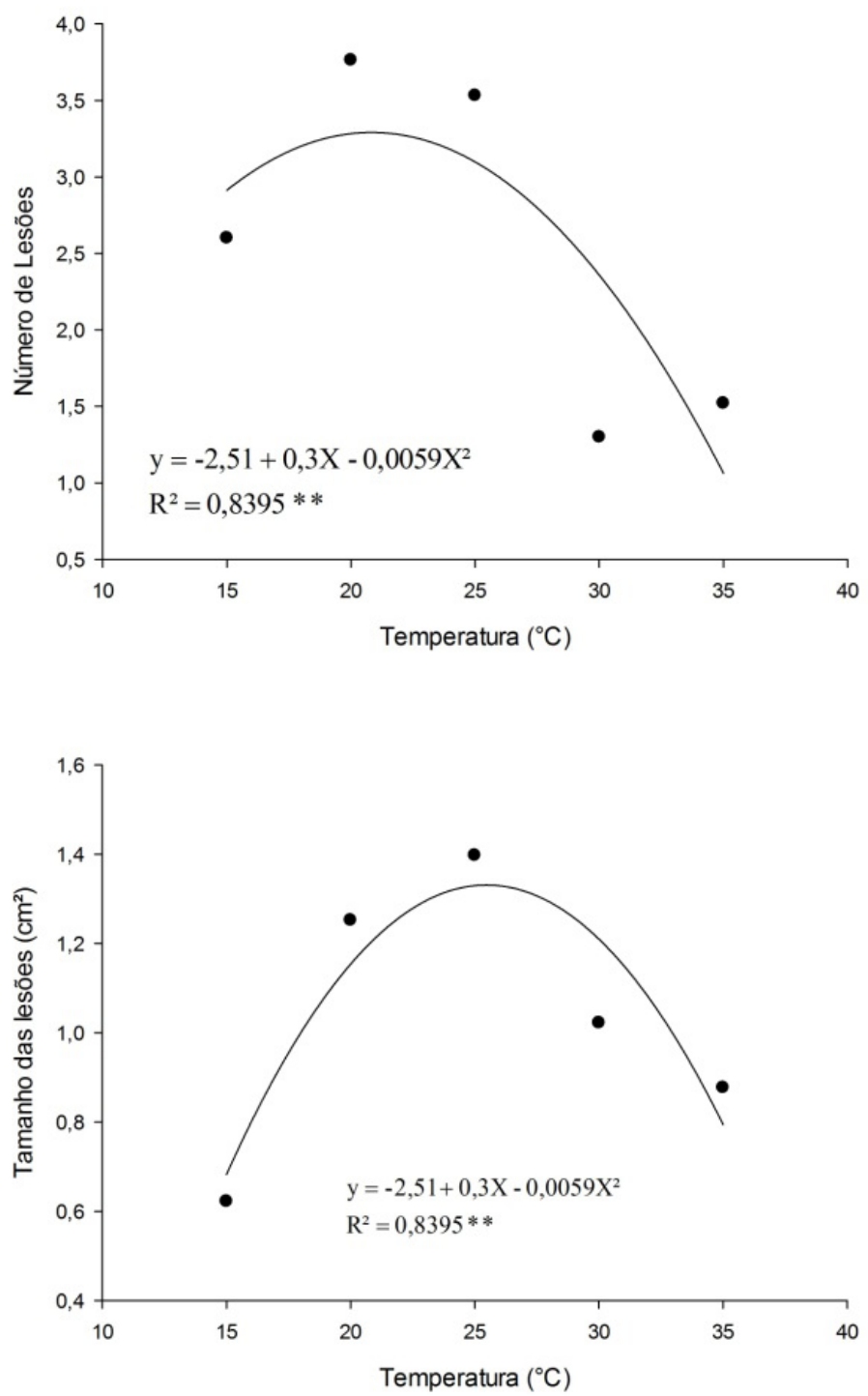

Figura 3. Número médio (A) e tamanho médio (B) de lesões de mancha-da-folha, em mudas de videira cv. Isabel submetida a diferentes temperaturas com 48 horas de incubação em resposta a infecção de $P$. vitis, no ultimo dia de avaliação. **Significativo a $1 \%$ de probabilidade. tempo maior à luz, (Figura 1A). Corroborando com Casa et al . (9) que observou que os conídios de $S$. macrospora e de $S$. maydis apresentaram uma maior velocidade de germinação na presença da luz.

Efeito da temperatura na infecção de $P$. vitis em videira cv. Isabel

Para a área sob a curva de progresso da doença, houve efeito quadrático da temperatura sobre a percentagem de germinação após 48 horas de incubação no escuro (Figura 2 A). A temperatura estimada para maior intensidade da doença medida pela AACPD da mancha-dafolha foi $22,9^{\circ} \mathrm{C}$.

As temperaturas estimadas para o maior número e tamanho médio de lesões foram de $20,7{ }^{\circ} \mathrm{C}$ e $25,4{ }^{\circ} \mathrm{C}$, respectivamente, após 48 horas de incubação no escuro (Figura $3 \mathrm{~A}$ e B). Para a variável número de lesões as temperaturas de 20 e $25{ }^{\circ} \mathrm{C}$ apresentaram maiores valores médios, de 4 a 3 lesões por folha, respectivamente.

Magalhães et al. (14), avaliando o efeito de alterações da temperatura na severidade do oídio, Uncinula necator (Schw.). Burril, em mudas de videira cv. Alicante Bouschet e Thompson Seedless, verificaram que os maiores níveis de infecção ocorreram em mudas submetidas a $26{ }^{\circ} \mathrm{C}$ e os menores a $31,8^{\circ} \mathrm{C}$. Os autores sugerem que os fatores climáticos, como a temperatura e a umidade relativa do ar, são os principais determinantes no processo de infecção do oídio da videira, Nessas condições, folhas de videira tornam-se infectadas em uma ampla faixa de temperatura entre $6{ }^{\circ} \mathrm{C}$ e $33^{\circ} \mathrm{C}$. Erincik et al. (10), ao estudar o efeito de diferentes temperaturas e diferentes períodos de molhamento foliar na infecção por Phomopsis viticola em videiras 'Catawba' ( . labrusca), verificaram que a temperatura máxima e mínima para ocorrer a infecção foi de aproximadamente 5 e $35^{\circ} \mathrm{C}$, respectivamente. A temperatura ótima para a infecção nas folhas está entre 16 a $20^{\circ} \mathrm{C}$.

Segundo Lalancette et al. (12) diversos modelos apontam que a duração do molhamento foliar, associada à temperatura, atua como fatores fundamentais para o processo de eficiência da infecção de doenças, como por exemplo o míldio da videira. Com água livre disponível, vários processos relacionados às infecções das doenças, incluindo a liberação e a germinação de esporos, a penetração do tubo germinativo de fungos e a multiplicação de células de fitobactérias, ficam apenas dependentes da temperatura para seu estabelecimento (1).

O meio ST acrescido de leite de coco (1\%) e extrato de uva (1\%) apresentou maior esporulação em 96 horas de incubação.

A maior porcentagem de germinação $(70 \%)$ foi observada na temperatura de $25^{\circ} \mathrm{C}$, após 12 horas de incubação no escuro, comprovando que a luz pode exercer efeito negativo sobre o $P$. vitis.

Os resultados obtidos no experimento em casa de vegetação as temperaturas de $20^{\circ} \mathrm{Ce} 15^{\circ} \mathrm{C}$ propiciaram a maior AACPD da manchada-folha após 48 horas de incubação na ausência de luz.

\section{REFERÊNCIAS BIBLIOGRÁFICAS}

1. Amorim, L.; Rezende, J.A.M., Bergamin Filho, A., Camargo, L.E.A. (Eds.) Manual de Fitopatologia. Doenças das Plantas Cultivadas. $4^{a}$. Ed. São Paulo SP. Ceres, 2011. 704p.

2. Angelotti, F., Magalhaes, E., Fernandes, H. A., Barros, J. R., Barbosa, L. G. 2010. Efeito da temperatura e da luz na germinação de conídios de Uncinula necator. In: XLIII Congresso Brasileiro de Fitopatologia. Brasília, Cuiabá. Tropical Plant Pathology., v. 35, 2010.

3. Ávila, Z.R.; Pitelli, R.A. Crescimento, esporulação e virulência do inóculo de Cercospora piaropi, agente de biocontrole do aguapé. Fitopatologia Brasileira, Brasilia, v.29, p.189-192, 2004. 
4. Bennett, J.; Jarvis, P.; Creasy, G.L.; Trought, M.C.T. Influence of defoliae tion on overwintering carbohydrate reserves, return bloom, and yield of mature Chardonnay grapevines. American Journal of Enology and Viticulture, Davis, v. 56, n. 4, p. 386-393, 2005.

5. Bogo, A.; Maffioletti, M. A.; Valdebenito-Sanhueza, R. M.; \& Casa, R. T. Caracterização morfológica de isolados de Cryptosporiopsis perennans em diferentes meios de cultura. Tropical Plant Pathology, Brasilia, v. 33, n. 3, p. 248-251, 2008.

6. Brunelli, K.R.; Fazza, A.C.; Athayde Sobrinho, C.; Camargo, L.E.A. Efeito do meio de cultura e do regime de luz na esporulação de Cercospora zeae-maydis. Summa Phytopathologica, Botucatu, v. 32, n. 1, p. 92-94, 2006.

7. Campbell, C.L.; Madden, L.V. Introduction to Plant Disease Epidemiology. New York: John. Wiley, 1990. 532p.

8. Carnaúba, J. P.; Sobral, M. F.; Amorim, E. D. R.; Silva, J. C. D.; Santos, V. B. D.; \& Félix, K. D. S. Avaliação de diferentes meios de cultura na esporulação de Scytalidium lignicola. Summa Phytopathol,Botucatu, v. 33, p. 199-200, 2007.

9. Casa, R.T.; Reis, E.M.; Zambolim, L.; Moreira, E.N. Efeito da temperatura e de regimes de luz no crescimento do micélio, germinação de conídios e esporulação de Stenocarpella macrospora e Stenocarpella maydis. Fitopatologia Brasileira, Brasilia, v. 32, n. 2, p. 137-142, 2007.

10. Erincink, O.; Madden, L.V., Ferree, D.C.; Ellis, M.A. Temperature and wetness-duration requirements for grape leaf and cane infection by Phomopsis viticola. Plant Disease, St. Paul, v. 87, n. 7, p. 832-840, 2003.

11. Ferreira, D.F. Sisvar: a computer statistical analysis system. Ciência e Agrotecnologia, Lavras, v. 35, n. 6, p. 1039-1042, 2011.

12. Lalancete, N.; Ellis, M.A.; Madden, L.V. Estimating infection efficiency of Plasmopara viticola on grape. Plant disease, St. Paul, 1987.

13. Lenz, G.; Costa, I.V.; Balardin, R.S.; Marques, L.N.; Arrué, A.; Stefanelo, M.S., Zemolin, C.R. Elaboração e validação de escala diagramática para quantificação da mancha de isariopsis da videira. Ciência Rural, Santa Maria, v. 39, n. 8, p. 2301-2308, 2009.

14. Magalhães, E.E.D.E.; Angelotti, F.; Peixoto, A.R.; Fernandes, H.A. Impacto de alterações da temperatura sobre a infecção do óidio da videira. In: Embrapa Semiárido-Artigo em anais de congresso (ALICE). Jaguariúna. Mudanças climáticas e problemas fitossanitários: Jaguariúna: Embrapa Meio Ambiente, 2012. Acesso em: 20/mai/2014

15. Marini, D.; Mensch, R.; Freiberger, M. B.; Dartora, J.; Franzener, G.; Garcia, R. C.; \& Stangarlin, J. R. Comunicação científica efeito antifúngico de extratos alcoólicos de própolis sobre patógenos da videira. Arq. Inst. Biol., São Paulo, v. 79, n. 2, p. 305-308, 2012.

16. Nozaki, M.H.; Camargo, M. E.; Barreto, M. Caracterização de Diaporthe citri em diferentes meios de cultura, condições de temperatura e luminosidade. Fitopato Bras, Brasilia, v. 29, n. 4, p. 429-432, 2004.

17. Santos, L. A.; de Souza, P. E.; Pozza, E. A.; Caldeira, D. M.; \& dos Santos Botelho, D. M. Nova técnica para isolar Cercospora coffeicola Berkeley \& Cooke, agente etiológico da cercosporiose do cafeeiro.Coffee Science, Lavras, v. 9, n. 1, p. 142-144, 2014.

18. Sisterna, M., \& Ronco, L. Occurrence of grapevine leaf spot caused by Pseudocercospora vitis in Argentina. Plant Pathology, London, v. 54, n. 2, p. 247-247, 2005.

19. Sônego, O.R.; Garrido, L. da R.; Junior Grigoletti, A. Doenças fúngicas. In: FARJADO, T.V.M. Uvas para o processamento. EMBRAPA UVA E VINHO, Bento Gonçalves, 131p., 2003,

\section{ERRATA}

\section{Na página 257, onde se lia:}

"Shwan-Estrada":

Aline José Maia ${ }^{1}$, Kátia Regina Freitas Shwan-Estrada ${ }^{2}$, Cacilda Márcia Duarte Rios Faria ${ }^{1}$, Leandro Alvarenga Santos ${ }^{1}$, Juliana Batista Santos Oliveira ${ }^{2}$, Rafaela Cristina dos Santos ${ }^{1}$

Maia, A.J.; Shwan-Estrada, K.R.F.; Faria, C.M.D.R.; Santos, L.A.; Oliveira, J.B.S.; Santos, R.C. Produção de esporos e efeito da temperatura e luminosidade sobre germinação e infecção de Pseudocercospora Vitis em videira. Summa Phytopathologica, v.41, n.4, p.287-291, 2015.

Maia, A.J.; Shwan-Estrada, K.R.F.; Faria, C.M.D.R.; Santos, L.A.; Oliveira, J.B.S.; Santos, R.C. Spore production and effect of temperature and light on germination and infection by Pseudocercospora vitis in grape plants. Summa Phytopathologica, v.41, n.4, p.287-291, 2015.

Leia-se:

"Schwan-Estrada":

Aline José Maia ${ }^{1}$, Kátia Regina Freitas Schwan-Estrada ${ }^{2}$, Cacilda Márcia Duarte Rios Faria ${ }^{1}$, Leandro Alvarenga Santos ${ }^{1}$, Juliana Batista Santos Oliveira ${ }^{2}$, Rafaela Cristina dos Santos ${ }^{1}$

Maia, A.J.; Schwan-Estrada, K.R.F.; Faria, C.M.D.R.; Santos, L.A.; Oliveira, J.B.S.; Santos, R.C. Produção de esporos e efeito da temperatura e luminosidade sobre germinação e infecção de Pseudocercospora Vitis em videira. Summa Phytopathologica, v.41, n.4, p.287-291, 2015.

Maia, A.J.; Schwan-Estrada, K.R.F.; Faria, C.M.D.R.; Santos, L.A.; Oliveira, J.B.S.; Santos, R.C. Spore production and effect of temperature and light on germination and infection by Pseudocercospora vitis in grape plants. Summa Phytopathologica, v.41, n.4, p.287-291, 2015.

Summa Phytopathologica, (2016) 42(2): 190 